ở tư thế gấp 90 độ. Bệnh nhân được tiến hành thay khớp khuỵu phải bán ràng buộc (semiconstrained). Sau mổ 2,1 năm cung vận động gấp duỗi đạt 120 độ, điểm Mayo đạt mức xuất sắc với 100 điểm, bệnh nhân có thể thực hiện mọi động tác trong sinh hoat hàng ngày mà không có trở ngại, không có bất kỳ biến chứng nào đến thời điểm theo dõi [7]. Kết quả này tốt hơn kết quả trung bình của chúng tôi một chút. Thang điểm Mayo trung bình của chúng tôi là 95 cũng đạt ở mức rất tốt, chỉ có 1 bệnh nhân khó khăn trong việc mặc áo. Cung vận động trung bình của 3 bệnh nhân chúng tôi là 108 độ. Thế hệ khớp của Ámbrosi sử dụng là thế hệ khớp thứ 2, có độ dơ nhất định trong quá trình gấp duỗi nên hạn chế lực tải lên khớp nên giảm được biến chứng nhanh lỏng chuôi và hao mòn khớp. Đây cũng là thế hệ khớp tương tự với thế hệ khớp của chúng tôi nên giảm được một phần nguy cơ lỏng khớp về sau.

\section{KẾT LUÂ̂N}

Thay khớp khuỷu toàn phân là một lựa chọn rất hiệu quả đối với các trường hợp cứng khớp, Mất vững khớp hoặc dính khớp khuỷu gây hạn chế vận động do di chứng chấn thương, nhẳm phục hồi hình thể và chức năng cho khớp khuỷu. Tuy nhiên để đạt kết quả tốt nhất cần đánh giá biên độ khớp khuỷu và các khớp lân cận cũng như có 1 kế hoạch chuẩn bị trước mổ chu đáo.

\section{TÀI LIÊU THAM KHẢO}

1. Prkic A, van CJA B, The B, Eygendaal D. Total elbow arthroplasty is moving forward: review on past, present and future. World J Orthop. 2016;7(1):44-9.

2. Dee $\mathbf{R}$. Total replacement arthroplasty of the elbow for rheumatoid arthritis. J Bone Joint Surg Br. 1972; 54:88-95.

3. "Mayo Elbow Performance Score" (2006), Journal of Orthopaedic Trauma. 20(7), S127.

4. Peden, J. P., \& Morrey, B. F. (2008). Total elbow replacement for the management of the ankylosed or fused elbow. The Journal of Bone and Joint Surgery. British Volume, 90-B(9), 1198-1204.

5. Morrey, B., Adams, R., \& Bryan, R. (1991). Total replacement for post-traumatic arthritis of the elbow. The Journal of Bone and Joint Surgery. British Volume, 73-B(4), 607-612.

6. Kodde, I. F., van Riet, R. P., \& Eygendaal, D. (2013). Semiconstrained Total Elbow Arthroplasty for Posttraumatic Arthritis or Deformities of the Elbow: A Prospective Study. The Journal of Hand Surgery, 38(7), 1377-1382.

7. D'Ambrosi, R., Formiconi, F., Ursino, N., \& Rubino, M. (2019). Treatment of complete ankylosed elbow with total arthroplasty. BMJ Case Reports, 12(7), e231123.

8. P.Y.Barthel, P.Mansat, F.Sirveaux et al (2014), Orthopaedics \& Traumatology: Surgery \& Research, Volume 100, Issue 1, 113-118.

\title{
TÌNH TRANG THIẾU VITAMIN A VÀ MộT Số YẾU TỐ LIÊN QUAN Ở TRẺ 7-9 TUÛ̉I TẠI HUYỆN PHÚ BÌNH, Tİ̉NH THÁI NGUYÊN, NĂM 2017
}

Hoàng Nguyễn Phương Linh, Nguyễn Song Tú1, Trần Thúy Nga', Nguyễn Thúy Anh ${ }^{1}$

\section{TÓM TẮT}

Thiếu vitamin A là vấn đề có ý nghĩa sức khỏe cộng đồng tại các nước thu nhập thấp và đang phát triển, trong đó có Việt Nam. Nhẳm xác định tình trạng thiếu vitamin $A$ và một số yếu tố liên quan ở trẻ 7-9 tuổi, nghiên cứu mô tả cắt ngang được tiến hành trên 716 tré có Zscore chiều cao/tuổi < -1 tại Thái Nguyên. Sử dụng phương pháp hỏi ghi, cân đo (cân nặng, chiều cao) và lấy máu xác định nồng độ vitamin $A$, sắt, kẽm huyết thanh và hemoglobin. Kết quả cho thấy tỷ lệ thiếu vitamin $A$ tiền lâm sàng (VAD-TLS) là $4,7 \%$, ở mức nhẹ có ý nghĩa sức khoẻ cộng đồng,

${ }^{1}$ Viện Dinh dưỡng Quốc gia, Hà Nội

Chịu trách nhiệm chính: Hoàng Nguyễn Phương Linh Email: hoangnguyenphuonglinh@dinhduong.org.vn Ngày nhận bài: 7.5.2021

Ngày phản biện khoa học: 21.6.2021

Ngày duyệt bài: 2.7.2021 nhưng tỷ lệ trẻ có VAD-TLS và nguy cơ VAD-TLS là $39,2 \%$. Nồng độ vitamin $A$ huyết thanh trung bình là $1,15 \pm 0,45 \mu \mathrm{mol} / \mathrm{L}$. Phân tích hồi qui logistic cho thây thiếu kẽm và suy dinh dưỡng (SDD) nhẹ cân có liên quan tới tỷ lệ VAD-TLS và nguy cơ VAD - TLS $(p<0,01)$. Trẻ SDD nhẹ cân có nguy cơ VAD-TLS cao hơn 1,6 lần nhóm không SDD $(p<0,01)$. Trẻ thiếu kẽm có nguy cơ VAD-TLS cao hơn 1,5 lần nhóm bình thường $(p<0,05)$.Vì vậy, cần triển khai can thiệp cải thiện tình trạng thiếu vi chất trên trẻ tuổi học đường, đặc biệt trên trẻ suy dinh dưỡng và nguy cở suy dinh dưỡng thấp còi.

Tư khoá: thiếu vitamin $A$, tiểu học, trẻ tuổi học đường, yếu tố liên quan, thấp còi.

\section{SUMMARY}

VITAMIN A DEFICIENCY STATUS AND RELATED FACTORS IN STUDENTS 7-9 YEARS OLD IN PHU BINH DISTRICT, THAI NGUYEN PROVINCE, 2017 
Vitamin A deficiency is a significant public health problem in low-income and developing countries, especially Vietnam. To identify vitamin A deficiency status and related factors in students 7-9 years old, a cross-sectional descriptive study was conducted in 716 students with the height for age Z-score $<-1$ in Thai Nguyen. Study used the questionnaire, weighing method (weight and height) and draw blood to determin the serum retinol, ferritin, zinc and hemoglobin concentrations. The result showed the prevalence of sub-clinical vitamin A deficiency (Sub VAD) was $4.7 \%$, at the mild level of public health significance problems, but the prevalence of risk of Sub VAD was $39.2 \%$. The mean serum retinol concentrations was $1.15 \pm 0.45 \mu \mathrm{mol} / \mathrm{L}$. The multivariate regression analysis showed a significant relationship between the zinc deficiency and underweight groups with vitamin A deficiency $(p<0.01)$. The prevalence of Sub VAD risk among the underweight group was 1.6 times higher than the standard group $(p<0.05)$. The prevalence of Sub VAD risk among the zinc deficiency group was 1.5 times higher than the normal group $(p<0.05)$. Therefore, an intervention for micronutrition deficiency among school-age children is necessary, especially in stunting risk and stunting children.

Keywords: Vitamin A deficiency, elemenatary school, school-age children, related factors, stunting.

\section{I. ĐĂT VẤN ĐỀ}

Thiếu vitamin A (Vitamin A deficiency - VAD) là nguyên nhân chính dẫn đến tình trạng quáng gà, mù loà, thiếu máu, suy giảm hệ miển dịch, nghiêm trong hơn là mắc các bênh truyền nhiễm và tử vong ở trẻ em tại các quốc gia thu nhập thấp và đang phát triển. Theo số liệu thống kê, tỷ lệ thiếu Vitamin A năm 2013 tai các nước thu nhập thấp và nước đang phát triển là $29 \%$, tỷ lệ quáng gà và tử vong ở trẻ do thiếu vitamin $\mathrm{A}$ lần lượt là $0,9 \%$ và $1,7 \%$ [1]. Tại Việt Nam, theo báo cáo điêuu tra năm 2015 của Viện Dinh dưỡng, tỷ lệ thiếu Vitamin $A$ tiên lâm sàng (VAD-TLS) ở nhóm dưới 5 tuổi là $13 \%$, trong đó trẻ miền núi là $16,1 \%$ [2]. Theo phân loại của Tổ chức $Y$ tế Thế giới (WHO) 2011, tỷ lệ thiếu VAD-TLS ở trẻ em Việt Nam đang ở mức trung bình (TB) có ý nghĩa sức khoẻ cộng đồng (SKCĐ).

Nguyên nhân dẩn đến việc thiếu vitamin $A$ chủ yếu là chế độ ăn uống không cung cấp đủ Vitamin $A$, trẻ mắc bênh nhiễm khuẩn làm tăng nhu cầu vitamin $A$. Thiếu vitamin $A$ khẩu phần dẫn đến cơ thể dự trữ vitamin $A$ thấp và không đáp ứng được nhu cầu cho cơ thể phát triển sinh lý, đặc biệt hoạt động của hệ thống thị giác, sự phát triển của các mô, việc chuyển hoá chất trong cơ thể và đề kháng nhiễm trùng. Các yếu tố nguy cơ dẫn đến tình trang VAD-TLS và nồng độ vitamin $A$ huyết thanh liên quan đến khu vực địa dư (thành thị/nông thôn) [2], vùng sinh thái, nhóm tuổi [3], lượng vitamin $A$ ăn vào, số đo vòng cánh tay, trình độ học vấn, thu nhập bình quân đầu người, sự thiếu máu và việc bổ sung vitamin $A$ [4]. Ngoài ra, trẻ SDD thấp còi và nhẹ cân có nguy cơ VAD-TLS cao hơn 1,7 lần nhóm không SDD hay đối tượng thiếu máu có nguy cơ VAD-TLS cao gấp 2,1 lần những đối tượng không thiếu máu [5].

Để có thể định hướng cho chiến lược can thiệp tình trạng thiếu vitamin $A$ ở trẻ tuổi học đưởng tại tỉnh Thái Nguyên nói riêng và các tỉnh vùng núi và cao nguyên phía Bắc nói chung, nghiên cứu được tiến hành nhằm đánh giá thực trạng thiếu vitamin $A$ và một số yếu tố liên quan ở trẻ 7-9 tuổi tại các trường tiểu học, thuộc huyện Phú Bình, tỉnh Thái Nguyên.

\section{II. ĐỐI TƯợNG VÀ PHƯƠNG PHÁP NGHIÊN CứU 2.1 Đối tượng, địa điểm và thời gian nghiên cứu:}

Đối tượng: Trẻ từ 84 -119 tháng tuổi (tức 79 tuổi) đáp ứng tiêu chí: Zsore chiều cao/tuổi (HAZ < -1); bố me đồng ý cho trẻ tham gia.

2.2 Địa điểm và thời gian: tại 6 trường tiểu học thuộc 5 xã của huyện Phú Bình, tỉnh Thái Nguyên trong thời gian tháng 02-03/ 2017.

Thiết kế nghiên cứu: Mô tả cắt ngang

2.3 Cỡ mẫu: Để xác định tỷ lệ VAD-TLS ở trẻ tiểu hoc

Áp dụng công thức:

$$
\mathrm{n}=\frac{\mathrm{Z}_{(1-\alpha / 2) \cdot \mathrm{p}(1-\mathrm{p})}^{\mathrm{d}^{2}}}{\mathrm{~d}^{2}}
$$

Trong đó: $\mathrm{n}$ là số đối tượng cần điều tra; tỷ lệ VAD-TLS tham khảo là 13,0\% [2]; chọn $\mathrm{d}=$ 0,$05 ; z$ có giá trị là 1,96 . DE (design effect) $=4$ (đảm bảo chọn mẫu cụm, đồng thời cõ mẫu đủ theo lớp tuổi và giới). Cỡ mẫu cần là 696 đối tượng. Dư phòng $5 \%$ bỏ cuộc nên cõ̃ mẫu cần điều tra là 730 đối tượng; Thực tế có 716 trẻ 7-9 tuổi đã được điều tra.

2.4. Phương pháp chon mẫu: Chon chỉ định huyện Phú Bình, Thái Nguyên, sau đó chọn chủ đích 5 xã có trường tiểu học, dân số đông, điều kiện kinh tế khó khăn của huyện.

Chọn trường: Chọn toàn bộ 6 trường tiểu học tại 5 xã.

Chọn đối tượng nghiên cứu: Toàn bộ 2.008 trẻ từ lớp 2 đến lớp 4 được sàng lọc, có 1.297 trẻ có Zscore HAZ <-1; khoảng cách $\mathrm{k}=$ 1297/730; chọn ngẫu nhiên hệ thống với khoảng cách $\mathrm{k}=1,8$; chọn được 730 trẻ. Thực tế thu thập được 716 trẻ. 
2.5 Phương pháp và công cụ thu thập số liệu, tiêu chuẩn đánh giá

+ Phỏng vấn: sử dụng bộ câu hỏi được thử nghiêm trước khi điều tra chính thức.

+ Cân đo nhân trắc: cân điện tử SECA có độ chính xác tới $0,1 \mathrm{~kg}$. Đo chiều cao đứng sử dụng thước gỗ 3 mảnh có độ chính xác tới $1 \mathrm{~mm}$.

+ Xét nghiệm máu: Định lượng vitamin A trong huyết thanh bằng phương pháp sắc ký lỏng hiệu năng cao (HPLC); Hemoglobin ( $\mathrm{Hb})$ trong máu bằng phương pháp Cyamethemoglobin, dùng máy Hemocue. Kẽm huyết thanh theo phương pháp quang phổ hấp phụ nguyên tử (AAS). Ferritin huyết thanh theo phương pháp xác định bản chất kháng thể đặc hiệu sử dung kit ELSA.

2.6 Một số tiêu chuẩn xác định, đánh giá

+ Cách tính tuổi: Tuổi của trẻ được tính theo WHO, 2006

+ Thiếu máu: khi hàm lượng Hemoglobin < $115 \mathrm{~g} / \mathrm{l}$ (WHO 2001);

+ Thiếu vitamin A tiền lâm sàng khi nồng độ vitamin A huyết thanh (Serum Retinol-SR) $<0,7 \mu \mathrm{mol} / \mathrm{l} ;$ Nguy cơ thiếu VA-TLS khi 0,7 $\mu \mathrm{mol} / \mathrm{I}$ $\leq \mathrm{SR}<1,05 \mu \mathrm{mol} / \mathrm{l}$ (WHO 2006). Thiếu kẽm khi nồng độ kẽm huyết thanh $<65 \mu \mathrm{g} / \mathrm{dL}$. Dự trữ sắt cạn kiệt khi hàm lượng Ferritin huyết thanh < 15 $\mathrm{mg} / \mathrm{L}$ (WHO, 2001)

+ Tình trạng dinh dưỡng trẻ: theo chuẩn tăng trưởng của WHO 2006. SDD nhẹ cân khi Z- score $\mathrm{CN} / \mathrm{T}<-2$; thấp còi khi Zscore $\mathrm{CC} / \mathrm{T}<-2$; gày còm khi Zscore $B M I / T<-2$.

2.7 Biến số nghiên cứu. Tỷ lệ VAD-TLS và nguy cơ VAD -TLS theo tuổi, giới, xã và tình trạng dinh dưỡng, thiếu vi chất dinh dưỡng; hàm lượng TB retinol huyết thanh (SR) theo tuổi, giới, tình trạng dinh dưỡng và thiếu vi chất dinh dưỡng.

2.8 Phân tích và xử lý số liệu: Sử dụng phần mềm Epi Data 3.1 để nhập liệu và SPSS 18.0 để phân tích. Số liệu nhân trắc được xử lý bằng phần mềm Anthro plus của WHO, 2006. Dùng test kiểm định: $\chi^{2}$ test để so sánh các tỷ lệ; $\mathrm{t}$ - test và ANOVA test so sánh giá trị trung bình (TB) 2 nhóm, nhiều nhóm với biến phân bố chuẩn; và phân tích hồi qui logistic dự đoán các yếu tố liên quan. Giá trị $p<0,05$ được xem có ý nghĩa thống kê (YNTK).

2.9 Đạo đức nghiên cứu: Nghiên cứu đã được chấp thuận bởi Hội đồng đạo đức của Viện Dinh dưỡng trước khi triển khai, theo quyết định số 152/QĐ-VDD ngày 13/2/2017.

\section{KẾT QUẢ NGHIÊN CỨU}

Nghiên cứu tiến hành trên 716 trẻ tai huyên Phú Bình. Trong đó có $49,9 \%$ là trẻ trai và $50,1 \%$ trẻ gái; độ tuổi trung bình của trẻ là 103,2 $\pm 9,6$ tháng. Có $14,8 \%$ gia đình của trẻ thuộc hộ nghèo (do UBND xã phân loại), 12,3\% là hộ cận nghèo, còn lại $72,9 \%$ bình thường. Dân tộc Kinh chiếm $89,4 \%$ còn lại $10,6 \%$ là dân tộc khác.

\subsection{Thực trạng thiếu vitamin A ở đối tượng nghiên cứu}

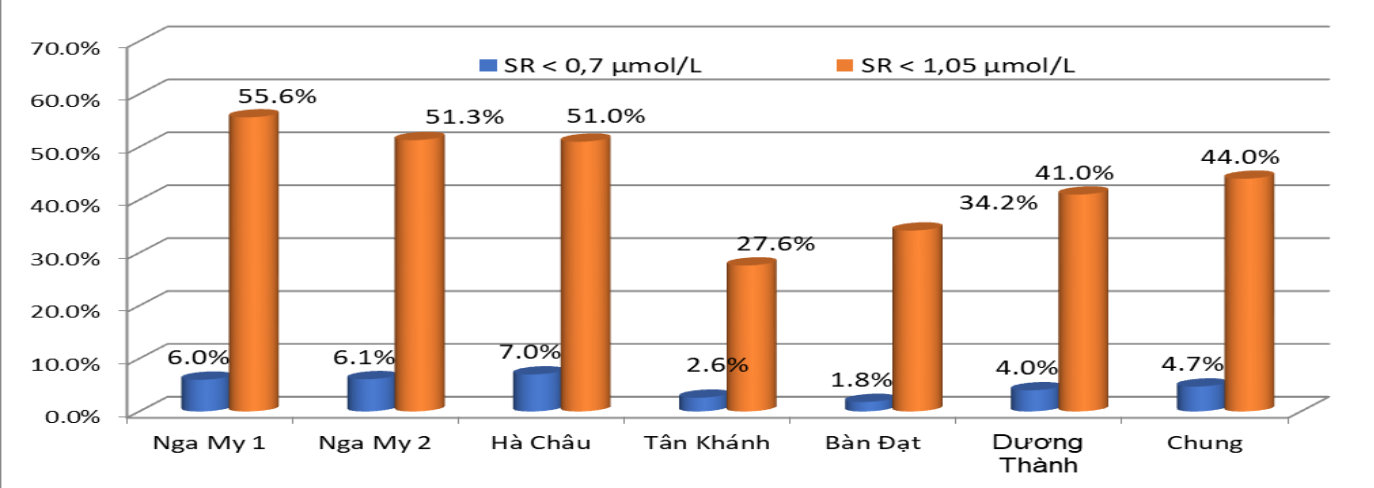

a: $\chi^{2}$ test, so sánh giữa các trường với $\mathrm{p}<0,001 ; \mathrm{SR}=$ Retinol huyết thanh

Hình 1. Tý lệ VAD-TLS và nguy cơ VAD-TLS đối tượng nghiên cứu theo trường $(n=716)$

Tỷ lệ trẻ VAD-TLS và nguy cơ VAD-TLS cao nhất ở nhóm trẻ trường Nga My $1(55,6 \%)$, và giảm xuống dần ở trẻ trường Nga My $2(51,3 \%)$, Hà Châu (51,0\%); tỷ lệ thấp nhất ở trẻ trường Tân Khánh $(27,6 \%)$. Có sự khác biệt có ý nghĩa về tỷ lệ này giữa các trường $\left(\chi^{2}\right.$ test, $\left.p<0,001\right)$.

Bảng 1. Tình trạng vitamin A của đối tướng nghiên cứu theo tuối, giới tính

\begin{tabular}{|c|c|c|c|c|}
\hline \multirow{2}{*}{ Các chỉ số } & \multirow{2}{*}{$\mathbf{n}$} & $\mathbf{2}$ & \multirow{2}{|c|}{$\begin{array}{c}\text { Giá trị SR(TB } \mathbf{S} \text { (TD) } \\
(\boldsymbol{\mu} \mathbf{m o l} / \mathbf{L})^{\mathbf{b}}\end{array}$} \\
\cline { 3 - 4 } & & $\mathbf{n}$ & $\mathbf{\%}$ & \\
\hline Trẻ 7 tuối & 204 & 7 & $3,4^{\mathrm{a}}$ & $1,15 \pm 0,49^{\mathrm{c}}$ \\
\hline Trẻ 8 tuối & 245 & 14 & 5,7 & $1,11 \pm 0,37$ \\
\hline
\end{tabular}




\begin{tabular}{|c|c|c|c|c|}
\hline Trẻ 9 tuổi & 267 & 13 & 4,9 & $1,19 \pm 0,48$ \\
\hline Trẻ trai & 357 & 19 & $5,3^{\mathrm{a}}$ & $1,16 \pm 0,49^{\mathrm{b}}$ \\
\hline Trẻ gái & 359 & 15 & $\mathbf{4 , 2}$ & $1,13 \pm 0,40$ \\
\hline Tống số & $\mathbf{7 1 6}$ & $\mathbf{3 4}$ & $\mathbf{4 , 7}$ & $\mathbf{1 , 1 5} \pm \mathbf{0 , 4 5}$ \\
\hline
\end{tabular}

a: $\chi^{2}$ test, $b$ : t-test so sánh theo nhóm tuối và giới với $p>0,05 ;$ c: ANOVA test

Tỷ lệ thiếu VAD-TLS ở đối tượng nghiên cứu (ĐTNC) là 4,7\%; nhưng tỷ lệ trẻ nguy cơ VAD-TLS rất cao $(44,0 \%)$. Nồng độ vitamin A huyết thanh TB là $1,15 \pm 0,45 \mu \mathrm{mol} / \mathrm{L}$. Khồng có sự khác biệt về tỷ lệ VAD-TLS và nồng độ vitamin $A$ huyết thanh theo tuổi và giới $(p>0,05)$.

3.2 Một số yếu tố liên quan đối với tình trạng thiếu vitamin A

Bảng 2. Tình trạng VAD TLS và nguy cơ VAD-TLS theo tình trạng dinh dữ̃ng

\begin{tabular}{|c|c|c|c|c|c|}
\hline Các thể SDD & $\mathbf{n}$ & $\begin{array}{c}\text { Số trẻ (SR } \\
<1,05 \\
\mu \mathrm{mol} / \mathrm{L}\end{array}$ & $\begin{array}{c}\text { Tỷ lệ trẻ VAD } \\
\text { và nguy cơ } \\
\text { VAD-TLS ( } \%)\end{array}$ & OR $(\stackrel{\mathbf{p}}{9} \% \mathrm{CI})^{\mathrm{a}}$ & $\begin{array}{l}\text { SR trung binh } \\
\text { (TB } \pm \text { SD) } \\
(\mu \mathrm{mol} / \mathrm{L})^{\mathrm{b}}\end{array}$ \\
\hline SDD nhẹ cân & 223 & 117 & $52,5^{a}$ & $0,003^{+}$ & $1,12 \pm 0,51$ \\
\hline Không SDD & 493 & 198 & 40,2 & $1,6(1,2-2,3)$ & $1,16 \pm 0,42$ \\
\hline SDD thấp còi & 118 & 52 & 44,1 & 1,00 & $1,13 \pm 0,41$ \\
\hline Không SDD & 598 & 263 & 44,0 & $1,0(0,67-1,49)$ & $1,15 \pm 0,46$ \\
\hline SDD gày còm & 60 & 30 & 50,0 & 0,399 & $1,14 \pm 0,52$ \\
\hline Không SDD & 656 & 285 & 43,4 & $1,3(0,77-2,2)$ & $1,15 \pm 0,46$ \\
\hline
\end{tabular}

${ }^{a}: \chi^{2}$ test với : ${ }^{+} p<0,05 ;$ b:t-test với $p>0,05 ;$.

Tỷ lệ VAD-TLS và nguy cơ VAD TLS ở nhóm trẻ SDD nhẹ cân là 52,5\%, ở nhóm không SDD là $40,2 \%$, có sự khác biệt có YNTK về tỷ lệ giữa 2 nhóm trẻ SDD nhẹ cân so với nhóm trẻ không SDD $\left(\chi^{2}\right.$ test, $\left.p<0,05\right)$. Nồng độ vitamin $A$ huyết thanh TB ở các nhóm trẻ SDD các thể không khác biệt có YNTK so với nhóm không SDD (t-test, $\mathrm{p}>0,05$ ).

Bảng 3. Tình trạng VAD TLS và nguy cơ VAD-TLS theo tình trạng thiêu vi chất dính dưỡng

\begin{tabular}{|c|c|c|c|c|c|}
\hline $\begin{array}{l}\text { Thiếu vi chất } \\
\text { dinh dương }\end{array}$ & $\mathbf{n}$ & $\begin{array}{c}\text { Số trẻ (SR } \\
<1,05 \\
\mu \mathrm{mol} / \mathrm{L}\end{array}$ & $\begin{array}{c}\text { Tỷ lệ trẻ VAD và } \\
\text { nguy cơ VAD- } \\
\text { TLS (\%) }\end{array}$ & OR $\left(95^{\mathbf{p}} \% \mathrm{CI}\right)^{\mathrm{a}}$ & $\begin{array}{l}\text { SR trung bình } \\
\text { (TB } \pm \text { SD }) \\
(\mu \mathrm{mol} / \mathrm{L})^{\mathrm{b}}\end{array}$ \\
\hline Thiếu máu & 170 & 84 & 49,4 & 0,123 & $1,08 \pm 0,40^{+}$ \\
\hline Bình thường & 546 & 231 & 42,3 & $1,3(0,94-1,88)$ & $1,17 \pm 0,46$ \\
\hline Thiếu kẽm & 424 & 203 & 47,9 & $0,015^{+}$ & $1,11 \pm 0,39^{++}$ \\
\hline Bình thường & 289 & 111 & 38,4 & $1,47(1,09-2,0)$ & $1,22 \pm 0,52$ \\
\hline Dự trữ sắt thấp & 122 & 58 & 47,5 & 0,466 & $1,08 \pm 0,25^{++}$ \\
\hline Bình thường & 587 & 255 & 43,4 & $1,2(0,80-1,70)$ & $1,16 \pm 0,48$ \\
\hline
\end{tabular}

a) $\chi^{2}$ test và b: t-test với ${ }^{+} p<0,05^{++} p<0,01$

Tỷ lệ VAD-TLS và nguy cơ VAD-TLS ở nhóm trẻ thiếu kẽm (nồng độ kẽm < $65 \mu \mathrm{g} / \mathrm{dL}$ ) là 47,9\% cao hơn nhóm bình thường $(38,4 \%)$ có YNTK $\left(\chi^{2}\right.$ test, $\left.p<0,05\right)$. Nông độ vitamin A huyết thanh TB ở nhóm trẻ thiếu máu, thiếu kẽm và dự trữ sắt thấp (Ferritin huyết thanh <30 $\mu \mathrm{g} / \mathrm{l}$ ) khác biệt có YNTK so với nhóm trẻ bình thường (t-test, $\mathrm{p}<0,05$ ).

Bảng 4. Mô hình hôi qui logistic đa biên dụ đoán các yêu tố liên quan với tình trạng VAD-TLS và nguy cơ VAD-TLS

\begin{tabular}{|c|c|c|c|c|}
\hline Các yếu tố trong mô hình (Biến độc lập) & OR (Hiệu chỉnh) & \multicolumn{2}{|c|}{$(95 \% \mathrm{CI})$} & $\mathbf{p}$ \\
\hline Giới tính của trẻ: Nam giới/nữ giới ${ }^{+}$ & 0,94 & 0,69 & 1,28 & 0,709 \\
\hline Tuối của mẹ: (dưới 30 và từ 30 tuổi trở lên)+ & 1,09 & 0,34 & 3,52 & 0,879 \\
\hline \multicolumn{5}{|l|}{ Trình độ học vấn mẹ } \\
\hline Cấp 2 trở xuống/trên cấp $2^{+}$ & 1,36 & 0,85 & 2,17 & 0,202 \\
\hline \multicolumn{5}{|l|}{ Hoàn cảnh kinh tế hộ gia đình } \\
\hline Nghèo, cận nghèo/bình thường ${ }^{+}$ & 0,90 & 0,63 & 1,28 & 0,544 \\
\hline Nghề nghiệp: Khác/làm ruộng ${ }^{+}$ & 0,97 & 0,69 & 1,36 & 0,865 \\
\hline Tình trạng thiếu máu: Thiếu máu/ Không thiếu ${ }^{+*}$ & 1,23 & 0,86 & 1,75 & 0,264 \\
\hline \multicolumn{5}{|l|}{ Tình trạng thiếu kẽm } \\
\hline Thiếu kẽm/không thiếu ${ }^{+}$ & $\mathbf{1 , 5 1}$ & 1,10 & 2,06 & 0,010 \\
\hline
\end{tabular}




\begin{tabular}{|c|c|c|c|c|}
\hline Tình trạng dự trữ sắt thấp & & & & \\
\hline Dự trữ thấp/không thấp ${ }^{+}$ & 1,11 & 0,74 & 1,66 & 0,621 \\
\hline Tình trạng SDD nhẹ cân & & & & \\
\hline SDD nhẹ cân/bình thường ${ }^{+}$ & $\mathbf{1 , 6 5}$ & $\mathbf{1 , 1 9}$ & $\mathbf{2 , 3 0}$ & $\mathbf{0 , 0 0 3}$ \\
\hline
\end{tabular}

Cõ̃ mẫu phân tích (n): 679; : Nhóm so sánh; *: có mối liên quan

Phân tích hồi qui đa biến dự đoán các yếu tố liên quan, cho thấy có mối liển quan giữa tình trạng thiếu kẽm $(p<0,01)$, tình trạng SDD nhẹ cân $(p<0,01)$ với tình trạng VAD-TLS và nguy cơ VAD-TLS sau khi kiểm soát với các yếu tố giới tính của trẻ, tuổi của mẹ, học vấn mẹ, kinh tế hộ gia đình, nghề nghiệp, tình trạng thiếu máu, dự trữ sắt thấp và SDD nhẹ cân.

\section{BÀN LUẬN}

4.1 Tình trạng VAD-TLS ở trẻ 7-9 tuổi tại huyện Phú Bình. Tỷ lệ VAD-TLS ở trẻ 7-9 tuổi có $\mathrm{HAZ}<-1$ là $4,7 \%$, ở mức nhe có ý nghĩa SKCĐ, thấp hơn so với điều tra ở Nghệ An trên trẻ từ 6-11 tuổi $(5,3 \%)[6]$ và Arnaud Lailou trên trẻ 6 - 75 tháng tuổi $(10,1 \%)$ ở 112 cụm của Việt Nam [7]. So với kết quả Tổng điều tra 2020, tỷ lệ VAD-TLS ở đối tượng nghiên cứu (ĐTNC) huyện Phú Bình thấp hơn so với tỷ lệ trẻ $<5$ tuối toàn quốc $(9,5 \%)$ và khu vực Miên núi phía Bắc $(13,8 \%)$ [8]. Tỷ lệ thiếu vitamin A ở trẻ không có sự khác biệt giữa nhóm tuổi và giới, cũng tương tự với kết quả điều tra ở huyện Nghĩa Đàn, tỉnh Nghệ $A n$ [6] và kết quả của nghiên cứu dinh dưỡng Đông Nam Á (SEANUT) [9]. Kết quả đồng thời cho thấy, tỷ lệ thiếu VAD - TLS ở Phú Bình thấp nhưng vẫn cần có giải pháp đảm bảo dinh dưỡng, duy trì tình trạng vitamin $A$ cho trẻ bởi tỷ lệ VAD-TLS và nguy cơ VAD-TLS của trẻ rất cao gần $44,0 \%$;

Có sự khác biệt có YNTK về tình trạng VADTLS và nguy cơ VAD-TLS giữa các trường; thậm chí có những trường tỷ lệ này cao hơn $50 \%$ và cao nhất là trường Nga My $1(55,6 \%)$, có trường thấp nhất 27,6\% (Tân Khánh). Điều đó cho thây rằng, tình trạng thiếu vitamin $A$ sẽ khác nhau theo địa bàn. Có thể lý giải sự khác biệt này bởi yếu tố môi trường, hoàn cảnh kinh tế, thói quen sinh hoạt, hay phong tục tập quán có sự khác biệt giữa các xã. Điều này phù hợp với kết luận của WHO về môi trường sinh thái, sự suy thoái của xã hội và kinh tế có ảnh hưởng tới tình trạng thiếu vitamin $A$.

4.2 Một số yếu tố liên quan đôii với tình trạng VAD-TLS và nguy cơ VAD-TLS ở trẻ 79 tuổi. Hàm lượng vitamin $A$ huyết thanh bị ảnh hưởng bởi tình trạng thiếu máu, thiếu kẽm và dự trữ sắt (bảng 3), tương tự nghiên cứu tại Nghệ An có yếu tố liên quan tới nồng độ vitamin $A$ với tình trạng thiếu kẽm và thiếu máu [6]. Thiếu vitamin $\mathrm{A}$ có thể góp phần gây thiếu máu do ảnh hưởng đến chuyển hóa sắt, tạo máu và tăng tính nhạy cảm với nhiễm trùng. Sự hấp thụ sắt bị suy giảm có thể do giảm các nguyên tố vi lượng như kẽm, được tìm thấy trong cấu trúc của các enzym điều phối hoặc xúc tác chuyển hóa sắt. Vì vậy, các can thiệp cải thiện tình trạng vitamin $A$ không thể là giải pháp đơn lẻ mà cần là giải pháp tổng thể cải thiện tình trang VCDD.

Mô hình quy hồi đa biến dự đoán yếu tố liên quan giữa tình trạng $V A D-T L S$ và nguy cơ VADTLS tại huyện Phú Bình đối với tình trạng thiếu kẽm và $S D D$ nhẹ cân ở trẻ. Nhóm trẻ SDD nhẹ cân có nguy cơ VAD-TLS cao hơn gấp 1,6 lần so với nhóm không SDD. Nhóm trẻ thiếu kẽm có nguy cơ VAD-TLS cao hơn gấp 1,5 lần so với nhóm bình thường. Điều đó cho thấy, tỷ lệ ngoài vấn đề cải thiện tình trạng dinh dưỡng, cải thiện tình trạng vi chất ở trẻ học đường cần được chú trọng giải quyết; đặc biệt là vấn đề thiếu kẽm nểu muốn cải thiện tình trang vitamin $\mathrm{A}$; Theo điều tra Quốc gia của Viện Dinh dưỡng 2010, lượng Vitamin $A$ chỉ đáp ứng được $65 \%$ nhu cầu hàng ngày của trẻ (vùng núi phía Bắc vitamin $\mathrm{A}$ động vật chỉ đáp ứng $34 \%$ nhu câu); nhu cầu sắt của khẩu phần ở mức $70 \%$, và $32 \%$ về kẽm; cho thấy cải thiện tình trạng vi chất là 1 mục tiêu đầy thách thức. Điều tra khẩu phần ăn trẻ tiểu học cho thấy khẩu phần năng lượng đạt khoảng $76 \%$ nhu câu khuyến nghị, sắt đạt $68 \%$; vitamin A đạt 54\%[9]. Như vậy, cải thiện tình trạng vitamin $\mathrm{A}$ trẻ em tuổi học đường cần thực hiện đảm bảo chất lượng bữa ăn cho trẻ học đường; đảm bảo các trường học có bữa ăn bán trú; đồng thời phải đây mạnh hoạt động truyền thông về nguy cơ thiếu vi chất dinh dưỡng, cung cấp kiến thức dinh dưỡng hợp lý.

\section{KẾT LUÂN}

Tỷ lệ thiếu vitamin $A$ tiền lâm sàng ở ĐTNC (VAD-TLS) là 4,7\%, ở mức nhẹ có ý nghĩa sức khoẻ cộng đồng. Tỷ lệ trẻ có nguy cơ VAD-TLS là $44,0 \%$. Nồng độ vitamin $A$ huyết thanh trung bình là $1,15 \pm 0,45 \mu \mathrm{mol} / \mathrm{L}$. Thiếu kẽm và suy dinh dương (SDD) nhẹ cân có liên quan tới tỷ lệ VAD-TLS và nguy cơ VAD - TLS $(p<0,01)$; Trẻ SDD nhẹ cân có nguy cơ VAD-TLS cao hơn 1,6 lần nhóm không SDD $(p<0,01)$. Trẻ thiếu kẽm có 
nguy cơ VAD-TLS cao hơn 1,5 lân nhóm bình thường $(p<0,05)$. Khuyến nghị cải thiện tình trạng vitamin A kết hợp với vi chất dinh dưỡng cho trẻ học đường để nâng cao tâm vóc và đảm bảo sự phát triển tốt nhất cho trẻ.

\section{TÀI LIÊU THAM KHẢO}

1. Stevens GA. Trends and mortality effects of vitamin A deficiency in children in 138 low-income and middle-income countries between 1991 and 2013: a pooled analysis of population-based surveys. Lancet Glob Health, 2015; 3(9): e528-36.

2. Viên Dinh Dưỡng. Đánh giá tình trang thiếu máu, thiếu một số vi chất dinh dưỡng của phụ nữ và trè em 6 - 59 tháng tai vùng thành thi, nông thôn và miền núi năm 2014 - 2015. Báo cáo đề tài nghiên cứu cấp Viện 2015.

3. Viện Dinh dưỡng, Tổng điều tra Dinh dưỡng 20009 - 2010. Nhà xuất bản Y học, 2010.

4. Yang $\mathbf{C}$, Chen $\mathbf{J}$, Liu $Z$ et al. Prevalence and influence factors of vitamin A deficiency of Chinese pregnant women. 2016. Nutr J. 2016; 15(1):12

5. Hoàng Văn Phượng, Lê Danh Tuyên, Trân Thúy $\mathbf{N g a}$, Nguyến Song Tú. Tình trang thiếu vitamin A và một số yếu tố liên quan ở trẻ 36-59 tháng tuổi nguy cơ suy dinh dưỡng thấp còi tai huyện đồng bằng sông Hồng, năm 2015. Tạp chí Ý hoc Việt Nam, 2017. Tập 458, (2): 216-220.

6. Bùi Thị Nhung, Lê Danh Tuyên, Cao Thị Thu Hương. Tình trạng thiếu vi chất dinh dưỡng của hoc sinh nguy cơ bi suy dinh dưỡng thấp còi và thấp còi tại huyện Nghĩa Đàn tỉnh Nghệ An năm 2013 - 2014. Táp chí Ý hoc dự phòng, 2017; 27: 32-37.

7. Laillou $\mathbf{A}$ et al. Micronutritent deficits are still public issues among women and young children in Vietnam. PlosOne, 2012; 7(4).

8. Viên Dinh dưỡng. Tông điều tra dinh dưỡng: mốt số kết quả chính 2019 - 2020. 2021

9. Le Nguyen BK, Le Thi $H$, Nguyen Do VA et al. Double burden of undernutrition and overnutrition in Vietnam in 2011: results of the SEANUTS study in 0.5-11-year-old children. $\mathrm{Br}$ J Nutr, 2013. 110 Suppl 3:S45-56.

\section{HIỆU QUẢ TƯ VẤN GIẢM GÁNH NĂNG CHĂM SÓC BỆNH NHÂN ALZHEIMER TẠI BỆNH VIỆN LÃO KHOA TRUNG ƯƠNG NĂM 2020 - 2021}

\section{TÓM TẮT}

Mục tiêu: Đánh giá hiệu quả tư vấn giảm gánh năng chăm sóc bệnh nhân Alzheimer và một số yếu tố liên quan. Đối tượng và phương pháp: Nghiên cứu can thiệp tư vấn giảm gánh nặng trên 52 người chăm sóc bênh nhân Alzheimer tai Bênh viên Lão Khoa Trung ương từ năm 2020 đển năm 2021. Đánh giá hiêu quả bằng thang điểm ZBI trước và 2 tuần sau tư vấn. Kết quả: Sau can thiệp gánh nặng chăm sóc giảm từ 43,7 điểm xuống còn 28,7 điểm theo ZBI. NCS lao động toàn thời gian có tỷ lệ cải thiện ZBI thấp hơn nhiêu so với nhóm cỏn lai $(p<0,05)$. Sư cải thiên ZBI cao hơn có ý nghĩa thống kê ở nhóm NCS có thời gian chăm sóc trong ngày kéo dài và bênh nhân SSTT giai đoạn vừa và nặng so với nhóm còn laai. Kết luận: Tư vấn giúp NCS giảm gánh nă̆ng chẳm sóc có ý nghĩa thống kê và liên quan đến đặc điểm giai đoạn bệnh, thời gian chăm sóc người bệnh và nghề nghiệp của NCS.

Tư khóa: Alzheimer, gánh nặng chăm sóc, thang điểm Zarit.

\section{SUMMARY}

\section{EFFECTIVE CONSULTING TO REDUCE THE}

\author{
${ }^{1}$ Bệnh viện Lão khoa Trung ương \\ ${ }^{2}$ Trường Đại họ Thăng Long \\ Chịu trách nhiệm chính: Nguyễn Ngọc Ánh \\ Email: ngocanh.nig@gmail.com \\ Ngày nhận bài: 5.5.2021 \\ Ngày phản biên khoa học: 22.6.2021 \\ Ngày duyệt bài: 2.7.2021
}

\section{Nguyễn Ngọc Ánh', Đỗ Thị Khánh Hỳ̃1,2 CAREGIVER BURDEN OF PATIENTS WITH ALZHEIMER'S DISEASE AT NATIONAL GERIATRIC HOSPITAL FROM 2020 TO 2021}

Objective: Effective evaluation consulting to reduce the burden of caring with Alzheimer's patients and related factors. Methods: An interventional study on 52 caregivers of Alzheimer's patients at National Geriatric Hospital from 2020 to 2021. Evaluation of effectiveness by ZBI scale before and 2 weeks after counseling. Results: After counseling, the burden of care decreased from 43.7 to 28.7 points according to ZBI $(p<0.05)$. The full-time jobs caregiver had a rate of improvement in ZBI lower than the other groups $(p<0.05)$. The improvement in ZBI was statistically significant in caregivers with prolonged day-to-day care and in patients with moderate and severe dementia conclusions: Counseling for the caregivers have reduced the burden significantly, that is related to the disease stage, patient care time per day or the occupation of caregivers.

Key words: Alzheimer, burden of caregiver, Zarit Burden Interview

\section{I. Đă̆T VẤN ĐỀ}

Ngày nay, tuổi tho tăng lên kéo theo sự gia tăng các bệnh lý thoái hóa, trong đó có các rối loạn sa sút trí tuệ. Trên thế giới ít nhất 50 triệu người đang sống chung với bệnh Alzheimer hoặc các chứng sa sút trí tuê khác và dự kiến có thề vượt quá 152 triệu người mắt vào năm 2050 [1]. Người bệnh Alzheimer đa số được chăm sóc tại nhà, người chăm sóc thường không được đào 